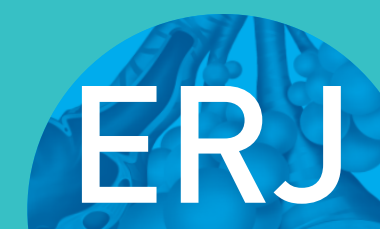

open research
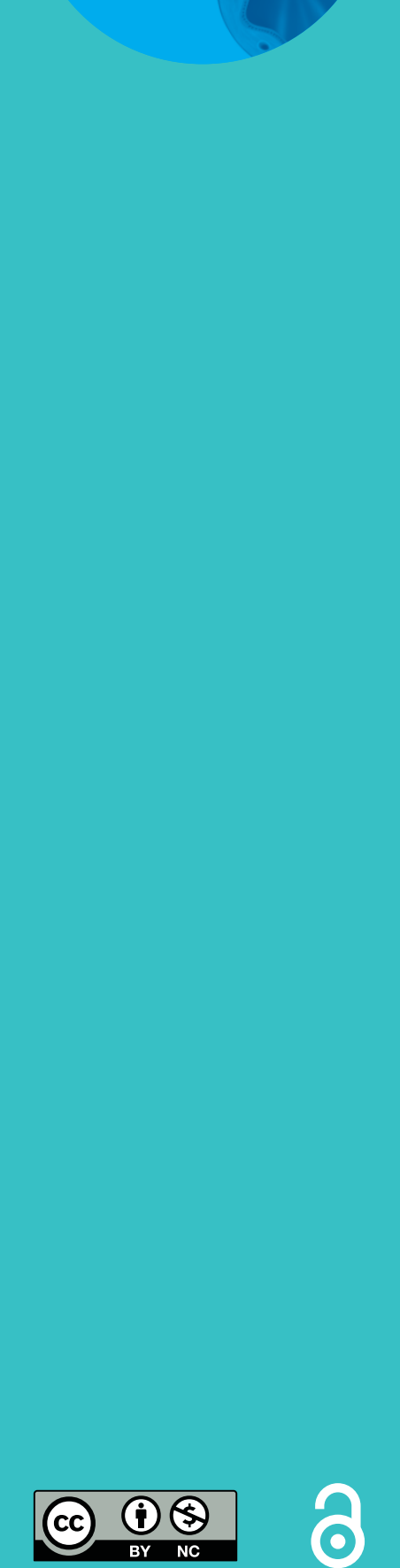

\section{Clinical profile of patients with adult-onset eosinophilic asthma}

\author{
Jantina C. de Groot ${ }^{1}$, Huib Storm², Marijke Amelink ${ }^{3}$, Selma B. de Nijs ${ }^{3}$, \\ Edwin Eichhorn ${ }^{4}$, Bennie H. Reitsma ${ }^{1}$, Elisabeth H.D. Bel ${ }^{3}$ and \\ Anneke ten Brinke ${ }^{1}$
}

Affiliations: ${ }^{1}$ Dept of Respiratory Medicine, Medical Centre Leeuwarden, Leeuwarden, The Netherlands. ${ }^{2}$ Dept of Clinical Chemistry, Medical Centre Leeuwarden, Leeuwarden, The Netherlands. ${ }^{3}$ Dept of Respiratory Medicine, Amsterdam Medical Centre, Amsterdam, The Netherlands. ${ }^{4}$ Dept of Ear, Nose and Throat Medicine, Medical Centre Leeuwarden, Leeuwarden, The Netherlands.

Correspondence: J.C. de Groot, Dept of Respiratory Medicine, Medical Centre Leeuwarden, Henri Dunantweg 2, 8934 AD Leeuwarden, The Netherlands. E-mail: christa_de_groot@yahoo.com

ABSTRACT Adult-onset eosinophilic asthma is increasingly recognised as a severe and difficult-to-treat subtype of asthma. In clinical practice, early recognition of patients with this asthma subtype is important because it may have treatment implications. Therefore, physicians need to know the distinct characteristics of this asthma phenotype. The objective of the present study was to determine the characteristic profile of patients with adult-onset eosinophilic asthma.

130 patients with adult-onset ( $>18$ years of age) asthma and high blood eosinophil counts $\left(\geqslant 0.3 \times 10^{9} \mathrm{~L}^{-1}\right)$ were compared with 361 adult-onset asthma patients with low $\left(<0.3 \times 10^{9} \mathrm{~L}^{-1}\right)$ blood eosinophils. Measurements included a series of clinical, functional and imaging parameters.

Patients with high blood eosinophils were more often male, had less well controlled asthma and higher exacerbation rates, despite the use of higher doses of inhaled corticosteroids. They had higher levels of total IgE without more sensitisation to common inhaled allergens. In addition, these patients had worse lung function, and more often showed fixed airflow limitation, air trapping, nasal polyposis and abnormalities on sinus computed tomography scanning. Chronic rhinosinusitis, air trapping and male sex were three independent factors associated with blood eosinophilia (adjusted OR 3.8 (95\% CI 1.7-8.1), 3.0 (95\% CI 1.1-8.1) and 2.4 (95\% CI 1.3-4.4), respectively).

Patients with adult-onset asthma with elevated blood eosinophils exhibit a distinct profile, which can readily be recognised in clinical practice.

@ERSpublications

Adult-onset eosinophilic asthma has a distinct clinical profile http://ow.ly/4mQSQk

This article has supplementary material available from openres.ersjournals.com

Received: Dec 152015 | Accepted after revision: April 082016

Clinical trial: This study is registered with the Netherlands Trial Register with identifier numbers NTR1846, NTR1838 and NTR2217

Conflict of interest: Disclosures can be found alongside this article at openres.ersjournals.com

Copyright $\odot$ ERS 2016. This article is open access and distributed under the terms of the Creative Commons Attribution Non-Commercial Licence 4.0. 


\section{Introduction}

Asthma is no longer considered a single disease and different phenotypes with potential underlying endotypes have been described over the last two decades [1-3]. Adult-onset eosinophilic asthma is increasingly recognised as one of the most severe and difficult-to-treat asthma subtypes [4-6]. This asthma subtype is associated with the development of persistent airflow limitation [7] and risk of severe exacerbations, yet symptoms are relatively mild and atypical [8]. Therefore, it is extremely important to recognise this relatively rare asthma subtype at an early phase of the disease. However, at asthma onset, these patients are older than classical atopic asthmatics, with relatively mild and atypical respiratory symptoms, and may therefore be easily misdiagnosed as having chronic obstructive pulmonary disease (COPD), which requires specific treatment that differs substantially from that of eosinophilic asthma.

It is important to examine whether these patients have distinct characteristics that could help the treating physician in making the correct diagnosis in clinical practice. This is even more important, since novel and very effective treatment options for this specific asthma subtype have recently become available [9-13]. By treating patients at an early stage, prevention of severe exacerbations and loss of lung function may then be achieved.

The present study was designed to investigate whether patients with adult-onset eosinophilic asthma have a different profile than those with noneosinophilic asthma, particularly with respect to demographics, respiratory allergies, aspirin intolerance, smoking history, comorbidity (obesity, gastro-oesophageal reflux disease (GORD) and sinonasal disease), disease severity and lung function (spirometry, fixed airflow limitation and air trapping).

\section{Methods}

\section{Patients}

491 patients with adult-onset (age $\geqslant 18$ years at diagnosis) asthma were consecutively included in the present study, which was part of a comprehensive research programme aimed at phenotyping and investigating mechanisms of patients with adult-onset asthma. Patients were recruited between June 2009 and February 2012 from one academic and four nonacademic pulmonary outpatient clinics in the Netherlands. Patients underwent extensive screening at entry into the study and were divided in those with high $\left(\geqslant 0.3 \times 10^{9} \mathrm{~L}^{-1}\right)$ or low $\left(<0.3 \times 10^{9} \mathrm{~L}^{-1}\right)$ levels of blood eosinophils $[9,11]$. All patients were on regular treatment with medium-high-dose inhaled corticosteroids, with or without oral corticosteroids. Asthma diagnosis was confirmed by a documented reversible airway obstruction (improvement in forced expiratory volume in $1 \mathrm{~s}(\mathrm{FEV} 1) \geqslant 12 \%$ predicted and $\geqslant 200 \mathrm{~mL}$ after administration of $400 \mu \mathrm{g}$ salbutamol) or by airway hyperresponsiveness to methacholine (reduction of $20 \%$ predicted in FEV1 after inhalation of up to $8 \mathrm{mg} \cdot \mathrm{mL}^{-1}$ methacholine). Patients had not experienced asthma exacerbations or respiratory tract infections in the 4 weeks before enrolment. Smokers and ex-smokers were allowed to participate in the study if they had distinct asthma symptoms, $\geqslant 12 \%$ reversibility in FEV1 and a normal diffusion capacity of carbon monoxide ( $\geqslant 80 \%$ predicted) at inclusion. Patients with pulmonary diseases other than asthma were excluded. The study was approved by the local medical ethical boards and written informed consent was obtained from every patient before enrolment. This study is registered with the Netherlands Trial Register with identifier numbers NTR1846, NTR1838 and NTR2217.

\section{Methods and design}

All patients underwent one extensive clinical, functional and laboratory assessment during one or two visits within 1 week. Data on demographics, medical history, smoking history, body mass index (BMI) and medication use were collected, and patients completed the Asthma Quality of Life Questionnaire [14], the Asthma Control Questionnaire (ACQ) [15] and the Sino-Nasal Outcome Test [16].

Peripheral blood cell counts were measured and expressed as absolute numbers. Atopic status was assessed by total and specific IgE to a panel of common aero- and food allergens and fungi. Atopy was defined as a score of $>0.35 \mathrm{kU} \cdot \mathrm{L}^{-1}$ for at least one of the specific IgE tested.

Lung function testing included spirometry before and after $400 \mu \mathrm{g}$ inhaled salbutamol [17], body plethysmography and single-breath carbon monoxide diffusion [18]. Residual volume (RV)/total lung capacity (TLC) (\% of predicted) was used as a parameter of air trapping. Air trapping was defined as RV/ TLC $\geqslant 120 \%$ predicted. Persistent airway obstruction was defined as FEV1/forced vital capacity (FVC) $<70 \%$ after administration of $400 \mu \mathrm{g}$ salbutamol.

Airway inflammation was assessed by the exhaled nitric oxide fraction (FeNO) [19] and differential cell counts in induced sputum [20]. A sputum eosinophil count of $\geqslant 3 \%$ was considered elevated [7, 21, 22].

Sinonasal involvement was assessed by computed tomography (CT) scanning and nasal endoscopy. Sinus CT was analysed and scored by an independent investigator using a validated scoring system [23]. Scores 
of $\geqslant 12$ were considered diagnostic of chronic rhinosinusitis [24]. Nasal endoscopy was performed by an experienced ear, nose and throat (ENT) specialist according to a standard scoring system [25] to identify nasal polyps and signs of rhinosinusitis.

\section{Statistical analysis}

Non-normally distributed data were logarithmically transformed before initial analysis. Patients with high $\left(\geqslant 0.3 \times 10^{9} \mathrm{~L}^{-1}\right)$ and low $\left(<0.3 \times 10^{9} \mathrm{~L}^{-1}\right)$ blood eosinophils were compared using two-sample t-tests, chi-squared analyses and nonparametric tests, where appropriate. Logistic regression analyses were performed and odds ratios for patients with high blood eosinophils versus those with low blood eosinophils as a reference group were obtained with one of the clinical factors potentially associated with blood eosinophilia as independent at a time in the model. In addition, a full multiple logistic regression analysis was applied with all significant factors forced into the model. A p-value $<0.05$ was considered as statistically significant. All analyses were performed using SPSS software, version 21 (IBM, Armonk, NY, USA).

\section{Results}

130 patients with adult-onset asthma had elevated levels of blood eosinophils. Their characteristics are shown in table $1.75 \%$ of the patients with high blood eosinophils also had elevated sputum eosinophils $(\geqslant 3 \%)$.

\section{Comparison of patients with high and low blood eosinophils}

Differences in clinical and inflammatory characteristics between patients with high versus low blood eosinophils are shown in table 1. Patients with high blood eosinophils had higher percentages of sputum eosinophils, higher FeNO and higher levels of total IgE. Patients with low eosinophils were more often female.

Features of asthma severity are represented in table 2. Patients with high blood eosinophils had more severe disease, with higher ACQ scores and higher exacerbation rates, and required higher doses of anti-inflammatory medication. Overall, lung function in this group showed more abnormalities, with lower FEV1, more fixed airway obstruction and more air trapping.

Data on comorbidity are shown in table 3 . In the total group, only $30.5 \%$ of the patients were atopic, with no difference between the patients with and without eosinophilia. Sinus CT scores were higher in the group with high blood eosinophils, representing more evidence of rhinosinusitis. In this group, 19 (27.9\%) patients had a sinus CT score $\geqslant 12$, as compared to $18(8.2 \%)$ patients in the noneosinophilic group $(\mathrm{p}<0.001)$. Nasal polyps were observed twice as often in the patients with high blood eosinophil levels.

\section{Factors associated with high blood eosinophils}

The results of the analysis regarding factors possibly associated with high levels of blood eosinophils are summarised in table 4 and figure 1. Elevated sinus CT score, elevated RV/TLC, nasal polyps, fixed airflow obstruction, frequent exacerbations and male sex were all significantly associated with blood eosinophilia.

\begin{tabular}{|c|c|c|c|c|}
\hline & Total group & Blood eosinophils $<0.3 \times 10^{9} \mathrm{~L}^{-1}$ & Blood eosinophils $\geqslant 0.3 \times 10^{9} \mathrm{~L}^{-1}$ & p-value \\
\hline Patients & 491 & 361 & 130 & \\
\hline Males & $39.3 \%$ & $34.9 \%$ & $51.5 \%$ & 0.001 \\
\hline Age years & $51.8 \pm 13.0$ & $50.9 \pm 13.5$ & $54.2 \pm 11.4$ & 0.012 \\
\hline Total smoking exposure pack-years & $1(0-12)$ & $1(0-13)$ & $2(0-9)$ & 0.880 \\
\hline Leukocytes $\times 10^{9} \mathrm{~L}^{-1}$ & $6.9(5.8-8.5)$ & $6.6(5.6-8.0)$ & $7.9(6.3-9.1)$ & $<0.001$ \\
\hline Blood neutrophils $\times 10^{9} \mathrm{~L}^{-1}$ & $4.0(3.1-5.2)$ & $4.0(3.0-5.1)$ & $4.1(3.3-5.4)$ & 0.115 \\
\hline Blood eosinophils $\times 10^{9} \mathrm{~L}^{-1}$ & $0.2(0.1-0.3)$ & $0.1(0.1-0.2)$ & $0.5(0.3-0.6)$ & $<0.001$ \\
\hline FeNO ppb & $22(13-41)$ & $18(12-33)$ & $40(23-74)$ & $<0.001$ \\
\hline Sputum neutrophils & $65.9 \%(43.9-82.4 \%)$ & $70.7 \%(47.9-84.6 \%)$ & $56.3 \%(33.3-77.8 \%)$ & 0.002 \\
\hline Sputum eosinophils & $0.8 \%(0.1-7.3 \%)$ & $0.4 \%(0-2.0 \%)$ & $11.7 \%(2.6-37.9 \%)$ & $<0.001$ \\
\hline
\end{tabular}




\section{TABLE 2 Features of asthma severity in patients with low $\left(<0.3 \times 10^{9} \mathrm{~L}^{-1}\right)$ versus high $\left(\geqslant 0.3 \times 10^{9} \mathrm{~L}^{-1}\right)$ blood eosinophil counts}

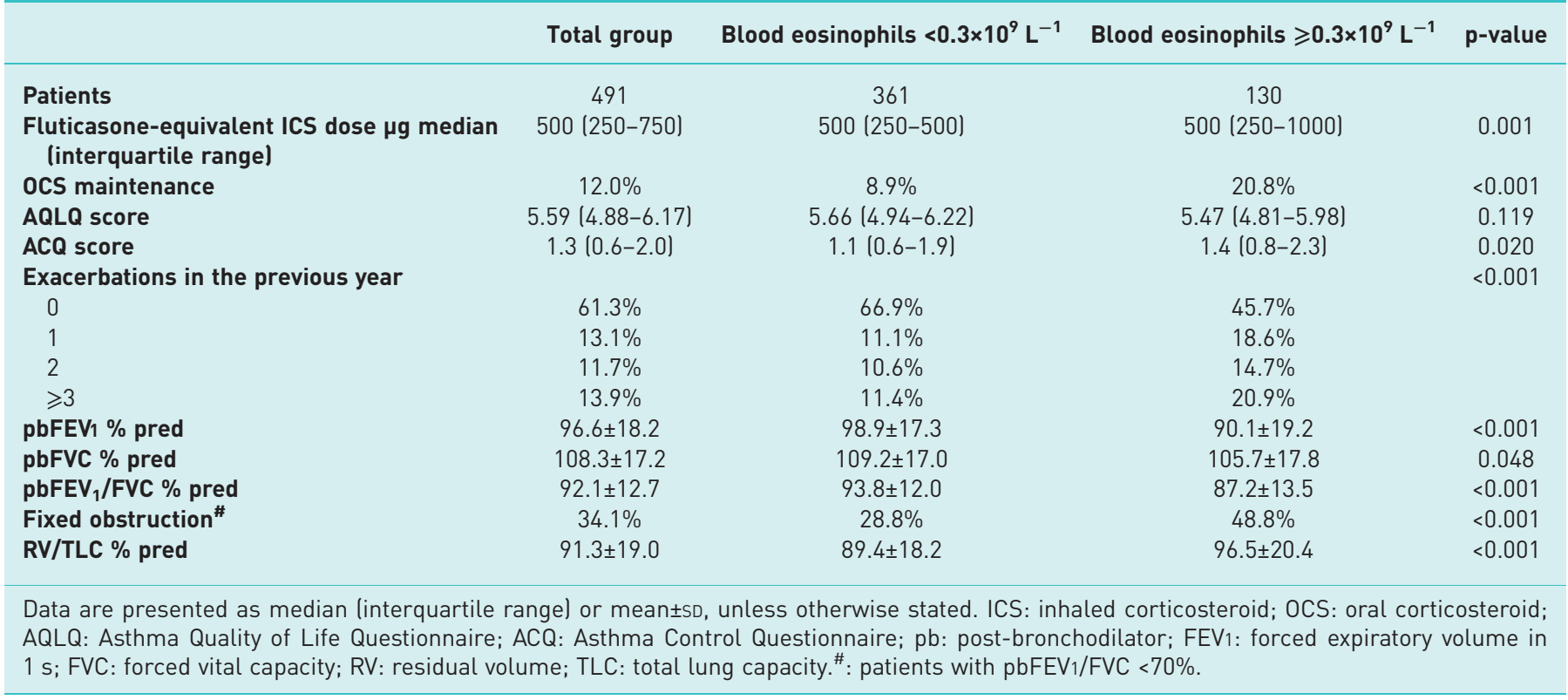

TABLE 3 Comorbidity in asthma patients with low $\left(<0.3 \times 10^{9} \mathrm{~L}^{-1}\right)$ versus high $\left(\geqslant 0.3 \times 10^{9} \mathrm{~L}^{-1}\right)$ blood eosinophil counts

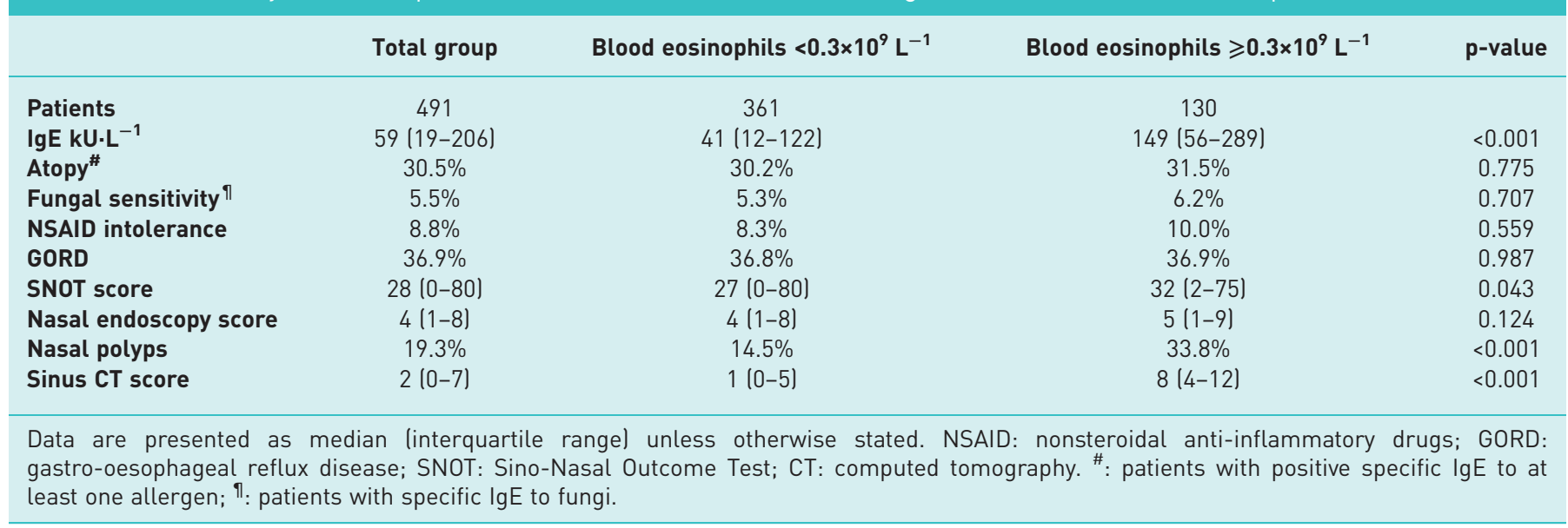

For the other factors, no significantly increased odds ratios were found. When analysing the six significant factors in one model, chronic rhinosinusitis (adjusted OR 3.8, 95\% CI 1.7-8.1), air trapping (adjusted OR 3.0, 95\% CI 1.1-8.1) and male sex (adjusted OR 2.4, 95\% CI 1.3-4.4) were the three independent factors associated with high blood eosinophils.

\section{Discussion}

The present study shows that patients with adult-onset eosinophilic asthma exhibit a distinct profile that can be recognised in clinical practice: male patients with frequent exacerbations, chronic rhinosinusitis with nasal polyposis, persistent airflow limitation and air trapping (figure 1). They also show worse asthma control with higher exacerbation rates and they are more often dependent on oral corticosteroids. Patients with persistent eosinophilia are not different from those without eosinophilia with respect to age of asthma onset, smoking history, respiratory allergies, aspirin intolerance, BMI and GORD.

Our study shows the distinct profile of patients with adult-onset eosinophilic asthma, which differs greatly from that of the general adult asthma population that consists mainly of patients with early-onset asthma. Most adults with asthma have had asthma since childhood, are atopic with typical symptoms, are female 


\section{TABLE 4 Odds ratios for factors potentially associated with high $\left(\geqslant 0.3 \times 10^{9} \mathrm{~L}^{-1}\right)$ blood}

\section{eosinophils}

OR $(95 \% \mathrm{CI})$

Sinus CT score ${ }^{\#} \geqslant 12$

$4.3(2.1-8.9)$

RV/TLC $\geqslant 120 \%$ pred

$3.1(1.6-6.0)$

Nasal polyps

$\mathrm{pbFEV}_{1} /$ FVC $<70 \%$

$3.0(1.7-5.5)$

$\geqslant 2$ exacerbations per year

$2.4(1.6-3.6)$

Male sex

$2.0(1.3-3.1)$

Age $\geqslant 50$ years

$B M I \geqslant 30 \mathrm{~kg} \cdot \mathrm{m}^{-2}$

Atopy"

$2.0(1.3-3.0)$

$1.4(0.9-2.1)$

$1.3(0.8-2.0)$

Ex- or current smoker

CT: computed tomography; RV: residual volume; TLC: total lung capacity; pb: post-bronchodilator; FEV1: forced expiratory volume in $1 \mathrm{~s}$; FVC: forced vital capacity; BMI: body mass index. \#: according to Lund-Mackay scoring system; " : patients positive for specific lgE to at least one inhaled allergen.

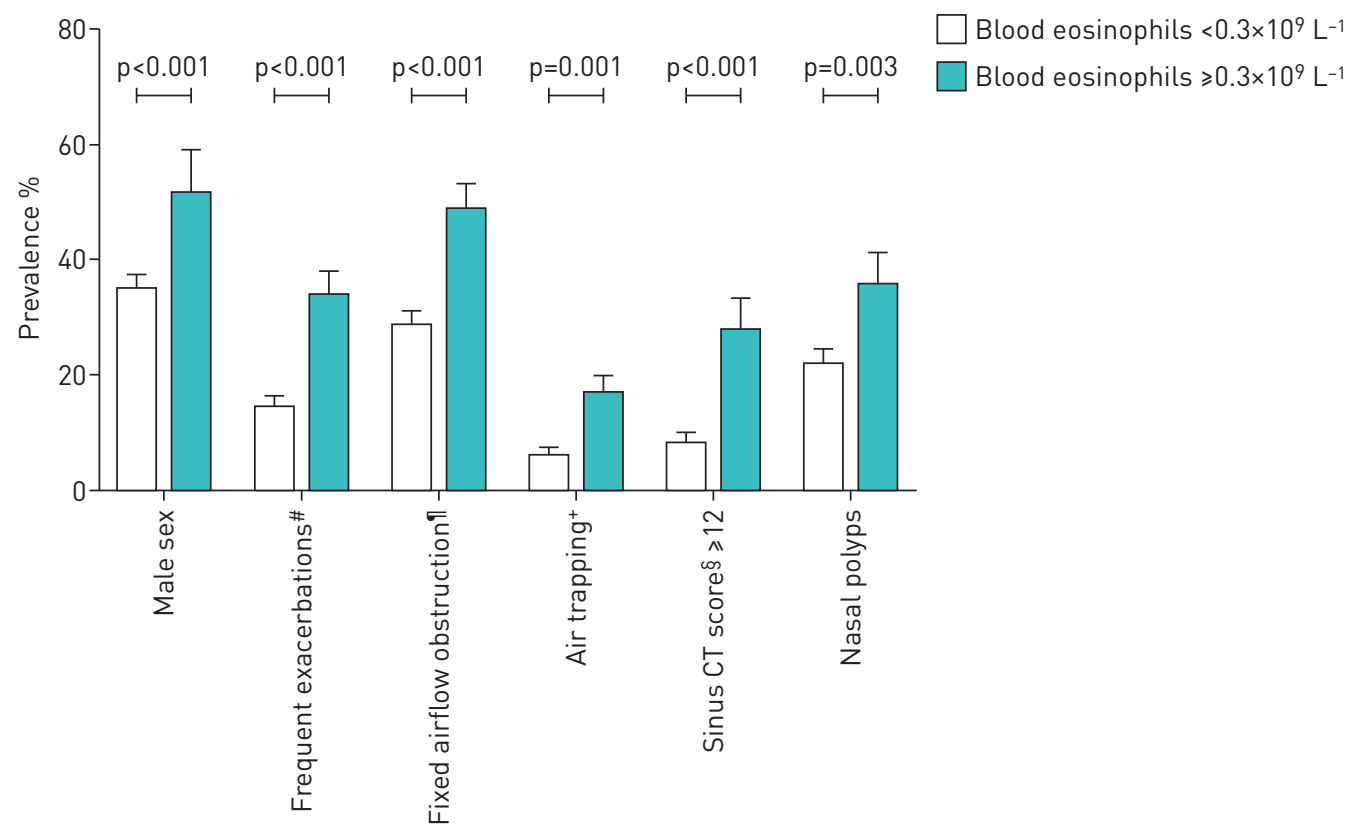

FIGURE 1 The characteristic profile of adult-onset eosinophilic asthma. Prevalence of distinct characteristics are shown for eosinophilic and noneosinophilic, adult-onset asthma patients. CT: computed tomography. \#: patients with two or more exacerbations per year; ": patients with post-bronchodilator forced expiratory volume in $1 \mathrm{~s} /$ forced vital capacity; ${ }^{+}$: patients with residual volume/total lung capacity $\geqslant 120 \%$ pred; $\S$ : according to Lund-Mackay scoring system.

and have fully reversible airflow limitation. This difference in patient characteristics is striking and it is therefore not surprising that patients with adult-onset eosinophilic asthma are often not recognised as asthma patients. However, the differentiation between patients with eosinophilic asthma and other airway diseases is essential, because they need more aggressive or targeted anti-inflammatory treatments. With the distinct profile of eosinophilic asthma in mind, it becomes much easier to recognise the asthma subtype and to provide the patients with the appropriate therapy.

Hypersensitivity to aspirin was not a characteristic of patients with eosinophilic asthma, as has been suggested previously [26]. In fact, the prevalence of adverse respiratory effects to aspirin was very low $(<10 \%)$, and was similar between eosinophilic and noneosinophilic adult-onset asthma. However, aspirin sensitivity was not tested with challenge tests and so it cannot be excluded that there might have been a bias as a result of under-reporting. 
One could argue that high levels of eosinophils are an expression of nonadherence to inhaled corticosteroid therapy. Although this cannot be excluded, it would not explain why patients with high blood eosinophil levels have more sinonasal disease, nasal polyposis, fixed airflow limitation and air trapping. These differences strongly suggest that adult-onset eosinophilic asthma is indeed a distinct asthma phenotype, probably with different underlying mechanisms. Still, poor adherence should always be considered before labelling a patient as having eosinophilic asthma.

We based our phenotypic profile on blood eosinophils rather than sputum eosinophils for two reasons. First, sputum induction facilities are not available in most clinics, and second, sputum induction is unsuccessful in a large proportion of patients. In our study, 62\% of the patients had an adequate sputum sample. Remarkably, $25 \%$ of patients with elevated levels of blood eosinophils had normal levels of sputum eosinophils, whilst $20 \%$ of patients with normal levels of blood eosinophils had raised levels of sputum eosinophils. Apparently, discrepancies exist between blood and sputum eosinophilia within the same patients. The reason for this discrepancy is unclear but might reflect a difference in eosinophil kinetics [27] or might result from topical treatment. For example, in some patients, inhaled corticosteroids might not reach distal airways or nasal sinuses, which might contribute to relatively high percentages of eosinophils in sputum. In other patients, topical corticosteroids might effectively reduce inflammation in the airways, without having any effect on systemic inflammation. Despite this discrepancy, the profile of patients in our cohort with persistent eosinophilia in blood or sputum were identical (supplementary table S1), indicating that both parameters can be used to identify the eosinophilic phenotype.

The cut-off value of $0.3 \times 10^{9} \mathrm{~L}^{-1}$ for blood eosinophils was based on previous studies describing patients with eosinophilic asthma $[11,28]$. However, in clinical practice, it would be more useful to have a "safety zone" of limit values between which the profile is most pronounced. Therefore, we performed a sensitivity analysis and found similar profiles when using cut-off values between $0.2 \times 10^{9}$ and $0.4 \times 10^{9} \mathrm{~L}^{-1}$, but below $0.2 \times 10^{9} \mathrm{~L}^{-1}$, the profile became much weaker and lost the characteristics of asthma severity. A table comparing five categories of increasing eosinophil values is provided in table S2.

Our study shows that eosinophilic asthma exhibits many characteristics of a systemic disease, with involvement of the entire airway from the nose to the smallest peripheral airways, as well as the bone marrow. The association between blood eosinophilia and peripheral airway obstruction has not been reported before but might explain why patients with eosinophilic asthma have relatively low asthma symptom scores [8]. Obstruction of the small airways ("silent zone") is indeed not associated with characteristic asthma attacks with wheezing, but rather with air trapping and dynamic hyperinflation. Involvement of peripheral airways makes this type of asthma difficult to control with local anti-inflammatory agents and it often requires systemic anti-inflammatory medication. This might explain why these patients are often oral corticosteroid-dependent and may also explain the added beneficial effect of the new injectable biologicals in patients who already using high doses of inhaled corticosteroids [9, 22].

In our patients with eosinophilic asthma, only one third of patients was sensitised to common inhaled allergens, a proportion similar to that observed in patients with low blood eosinophils. However, most of the nonsensitised patients with eosinophilic asthma had elevated levels of total IgE, which might point to hidden allergens, for example, sensitising substances that occur in polluted air [29] or superantigens against Staphylococcus aureus, which have been implicated in the pathophysiology of chronic rhinosinusitis with nasal polyposis $[30,31]$. This fits in with our observation that patients with high IgE levels $\left(\geqslant 100 \mathrm{kU} \cdot \mathrm{L}^{-1}\right)$ had six times higher sinus CT scores and nasal polyps more than twice as often than patients with low IgE levels.

How can we put our findings into perspective with the current understanding of asthma phenotypes and endotypes? Recent evidence suggests that this phenotype has a distinct molecular mechanism apart from allergy, in which the newly identified innate lymphoid cells type 2 (ILC2) might have a central role in driving eosinophilic inflammation [32]. ILC2 can be activated in an allergen independent way upon stimulation by viruses, fungal allergens and air pollutants [33], producing high amounts of type 2 cytokines like interleukins 5 and 13. Thus, a distinct endotype might be driving eosinophilia in this adult-onset asthma phenotype.

Our findings are particularly relevant for practicing physicians. On the one hand, physicians should be alerted by the combination of frequent exacerbations, chronic sinus symptoms and persistent airflow limitation in adults with new-onset respiratory symptoms, in particular in patients with no or only limited cigarette exposure, because this might be a manifestation of adult-onset eosinophilic asthma, and should not be diagnosed and treated as COPD. According to recent asthma guidelines, these patients might be diagnosed with so called asthma-COPD overlap syndrome. Our data underscore the importance of measuring blood eosinophils in these patients. Early recognition of eosinophilic asthma in adults with new-onset airway disease is important because this asthma phenotype is more difficult to control, requires higher levels of anti-inflammatory treatment, and is associated with more frequent exacerbations and a 
poorer quality of life than other asthma subtypes. It is important to evaluate for sinonasal disease and peripheral airways involvement in these patients. Polypous sinus disease might require referral to an ENT specialist and, if necessary, sinus surgery. Peripheral airway involvement, as reflected by increased residual volume and air trapping, is often accompanied by dynamic hyperinflation and reduced exercise intolerance. Treatment with extra-fine inhaled corticosteroids or systemic anti-inflammatory agents might be helpful in this case [34].

In conclusion, we have shown that patients with adult-onset eosinophilic asthma exhibit a distinct profile of male patients with frequent exacerbations, chronic rhinosinusitis with nasal polyposis, persistent airflow limitation and air trapping, which is strikingly different from the characteristics of the general adult asthma population. For the clinician, it is important to identify patients with this adult asthma phenotype at an early stage, because these patients may require targeted treatment to prevent exacerbations and poor asthma outcome.

\section{References}

1 Anderson GP. Endotyping asthma: new insights into key pathogenic mechanisms in a complex, heterogeneous disease. Lancet 2008; 372: 1107-1119.

2 Bel EH. Clinical phenotypes of asthma. Curr Opin Pulm Med 2004; 10: 44-50.

3 Gauthier M, Ray A, Wenzel SE. Evolving concepts of asthma. Am J Respir Crit Care Med 2015; 192: 660-668.

4 Amelink M, de Groot JC, de Nijs SB, et al. Severe adult-onset asthma: a distinct phenotype. J Allergy Clin Immunol 2013; 132: 336-341.

5 Fajt ML, Wenzel SE. Asthma phenotypes and the use of biologic medications in asthma and allergic disease: the next steps toward personalized care. J Allergy Clin Immunol 2015; 135: 299-310.

6 de Groot JC, ten Brinke A, Bel EHD. Management of the patient with eosinophilic asthma: a new era begins. Eur Respir J Open Res 2015; 1: 00024-2015.

7 ten Brinke A, Zwinderman AH, Sterk PJ, et al. Factors associated with persistent airflow limitation in severe asthma. Am J Respir Crit Care Med 2001; 164: 744-748.

8 Haldar P, Pavord ID, Shaw DE, et al. Cluster analysis and clinical asthma phenotypes. Am J Respir Crit Care Med 2008; 178: 218-224.

9 Bel EH, Wenzel SE, Thompson PJ, et al. Oral glucocorticoid-sparing effect of mepolizumab in eosinophilic asthma. N Engl J Med 2014; 371: 1189-1197.

10 Nair P, Pizzichini MM, Kjarsgaard M, et al. Mepolizumab for prednisone-dependent asthma with sputum eosinophilia. N Engl J Med 2009; 360: 985-993.

11 Pavord ID, Korn S, Howarth P, et al. Mepolizumab for severe eosinophilic asthma (DREAM): a multicentre, double-blind, placebo-controlled trial. Lancet 2012; 380: 651-659.

12 Castro M, Zangrilli J, Wechsler ME, et al. Reslizumab for inadequately controlled asthma with elevated blood eosinophil counts: results from two multicentre, parallel, double-blind, randomised, placebo-controlled, phase 3 trials. Lancet Respir Med 2015; 3: 355-366.

13 Laviolette M, Gossage DL, Gauvreau G, et al. Effects of benralizumab on airway eosinophils in asthmatic patients with sputum eosinophilia. J Allergy Clin Immunol 2013; 132: 1086-96.e5.

14 Juniper EF, Svensson K, Mork AC, et al. Modification of the asthma quality of life questionnaire (standardised) for patients 12 years and older. Health Qual Life Outcomes 2005; 3: 58.

15 Juniper EF, O’Byrne PM, Guyatt GH, et al. Development and validation of a questionnaire to measure asthma control. Eur Respir J 1999; 14: 902-907.

16 Piccirillo JF, Merritt MG Jr, Richards ML. Psychometric and clinimetric validity of the 20-Item Sino-Nasal Outcome Test (SNOT-20). Otolaryngol Head Neck Surg 2002; 126: 41-47.

17 Miller MR, Hankinson J, Brusasco V, et al. Standardisation of spirometry. Eur Respir J 2005; 26: 319-338.

18 Macintyre N, Crapo RO, Viegi G, et al. Standardisation of the single-breath determination of carbon monoxide uptake in the lung. Eur Respir J 2005; 26: 720-735.

19 ATS/ERS recommendations for standardized procedures for the online and offline measurement of exhaled lower respiratory nitric oxide and nasal nitric oxide, 2005. Am J Respir Crit Care Med 2005; 171: 912-930.

20 ten Brinke A, de Lange C, Zwinderman AH, et al. Sputum induction in severe asthma by a standardized protocol: predictors of excessive bronchoconstriction. Am J Respir Crit Care Med 2001; 164: 749-753.

21 Green RH, Brightling CE, McKenna S, et al. Asthma exacerbations and sputum eosinophil counts: a randomised controlled trial. Lancet 2002; 360: 1715-1721.

22 Haldar P, Brightling CE, Hargadon B, et al. Mepolizumab and exacerbations of refractory eosinophilic asthma. N Engl J Med 2009; 360: 973-984.

23 Lund VJ, Mackay IS. Staging in rhinosinusitus. Rhinology 1993; 31: 183-184.

24 Newman LJ, Platts-Mills TA, Phillips CD, et al. Chronic sinusitis. Relationship of computed tomographic findings to allergy, asthma, and eosinophilia. JAMA 1994; 271: 363-367.

25 Lund VJ, Kennedy DW. Quantification for staging sinusitis. The Staging and Therapy Group. Ann Otol Rhinol Laryngol Suppl 1995; 167: 17-21.

26 Szczeklik A, Stevenson DD. Aspirin-induced asthma: advances in pathogenesis and management. J Allergy Clin Immunol 1999; 104: 5-13.

27 Belda J, Margarit G, Martinez C, et al. Anti-inflammatory effects of high-dose inhaled fluticasone versus oral prednisone in asthma exacerbations. Eur Respir J 2007; 30: 1143-1149.

28 Ortega HG, Liu MC, Pavord ID, et al. Mepolizumab treatment in patients with severe eosinophilic asthma. $N$ Engl J Med 2014; 371: 1198-1207.

29 Takenaka H, Zhang K, Diaz-Sanchez D, et al. Enhanced human IgE production results from exposure to the aromatic hydrocarbons from diesel exhaust: direct effects on B-cell IgE production. J Allergy Clin Immunol 1995; 95: 103-115. 
30 Barnes PJ. Intrinsic asthma: not so different from allergic asthma but driven by superantigens? Clin Exp Allergy 2009; 39: 1145-1151.

31 Bachert C, Zhang N, Patou J, et al. Role of staphylococcal superantigens in upper airway disease. Curr Opin Allergy Clin Immunol 2008; 8: 34-38.

32 Brusselle GG, Maes T, Bracke KR. Eosinophils in the spotlight: eosinophilic airway inflammation in nonallergic asthma. Nat Med 2013; 19: 977-979.

33 Walker JA, Barlow JL, McKenzie AN. Innate lymphoid cells - how did we miss them? Nat Rev Immunol 2013; 13 75-87.

34 Popov TA, Petrova D, Kralimarkova TZ, et al. Real life clinical study design supporting the effectiveness of extra-fine inhaled beclomethasone/formoterol at the level of small airways of asthmatics. Pulm Pharmacol Ther 2013; 26: 624-629. 